\title{
As Interfaces da Relação Rural - Urbano no Brasil: Notas para Debate
}

\author{
Las Interfaces de La Relación Rural-Urbana en Brasil: \\ Notas para el Debate
}

\section{The interfaces of the Rural-Urban relationship in Brazil: notes for debate}

\author{
Celbo Antonio Ramos Fonseca Rosas \\ celboantonio@yahoo.com.br \\ Universidade Estadual de Ponta Grossa
}

\begin{abstract}
Resumo: O rural e o urbano sempre tiveram, em seus sentidos, significados distintos e antagônicos, ocasionando o surgimento de uma dicotomia analítica e conceitual sobre a temática, correlacionada com o uso específico dos espaços. O objetivo deste artigo é apontar algumas notas para debate e verificar, diante das principais correntes teóricas, as relações e necessidades encontradas pelas sociedades dos espaços rural e urbano, evidenciando as transformações no uso das técnicas a partir de meados do século XX no Brasil. Constata-se que o espaço rural é o que mais sofre consequências diante da realidade brasileira, sendo que as famílias que vivem essa realidade necessitam de alternativas para a superação das dificuldades produtivas e consequente geração de renda no âmbito do grande capital que se expande no território nacional.
\end{abstract}

Palavras-chave: Relação rural-urbano. Dicotomia. Território.

Resumen: En sus respectivos sentidos, lo rural y lo urbano siempre tuvieron significados distintos y antagónicos, que surgen de una dicotomía analítica y conceptual sobre el tema y que se correlacionan con el uso específico de los espacios. El propósito de este artículo es señalar algunas notas para el debate y, sobre las principales corrientes teóricas, verificar las relaciones y las necesidades que enfrentan las sociedades en las zonas rurales y urbanas, lo que evidencia los cambios en el uso de técnicas a partir de mediados del siglo XX en Brasil. Nos damos cuenta de que el espacio rural es el que sufre la mayoría de las consecuencias en la realidad brasileña, y las familias que viven esta realidad necesitan alternativas a las dificultades de producción y de generación de ingresos en el ámbito de un capital importante que se expande a nivel nacional.

Palabras clave: Relación rural-urbana. Dicotomía. Territorio.

Abstract: In their significations, the rural and urban have always had distinct and antagonistic meanings, with an analytical and conceptual dichotomy emerging regarding their relationship, correlated with the specific use of these spaces. The purpose of this article is to indicate some areas for discussion and, in the light of the main theoretical lines of approach, to verify the relationships and needs of societies in rural and urban areas, evidencing changes in the use of the techniques with effect from the mid-twentieth century in Brazil. It should be noted that, given the situation 
on the ground in Brazil, rural areas are those that most suffer adverse consequences, and the families that live in these areas need alternatives to the difficulties they face in production and income generation within the context of big business, which is expanding across the country.

Keywords: Rural-urban relationship. Dichotomy. Territory.

\section{INTRODUÇÃO}

O objetivo deste artigo é realizar apontamentos não definitivos sobre estudos referentes à relação entre os espaços rural e urbano, apresentando as principais correntes teóricas e referências que balizam seu entendimento, através da verificação desses espaços usados sob diferentes enfoques no território brasileiro.

Tal trabalho foi escrito com base nas discussões e reflexões realizadas na tese de doutorado defendida pelo autor (ROSAS, 2010), e na perspectiva de indicar áreas de pesquisa conjunta e metodologias, apontando direcionamentos que consideram a realidade sob o enfoque da relação entre o rural e o urbano.

Para verificar e compreender tais espaços, acreditamos que o ponto de referência seja o espaço rural, pois o urbano foi construído a partir das transformações do rural, ou seja, o urbano é o rural transformado. Nessa perspectiva, não é o rural que avança no urbano, mas o urbano que transformou e transforma o rural em diversas vertentes, principalmente a econômica, pois consideramos o urbano como centro econômico em seus diversos aspectos, como o comercial, de poder, entre outros, uma vez que, na maioria dos casos, as cidades são os centros decisórios e centralizadores da visão contemporânea pós-paradigmática da revolução industrial.

Embora alguns espaços rurais representem uma dinâmica capitalizada e expropriante, o poder de decisão e a vertente direcionadora dos investimentos econômicos ainda estão nas cidades, já que o produto final da maioria das atividades do campo está direcionado aos moradores das cidades, in natura ou processados, por necessidade ou por desconhecimento da memória daqueles que construíram o rural.

Ressaltamos também que o rural e a natureza são elementos imbricados, que se sobrepõem a partir de atividades extrativistas, agroecológicas ou preservacionistas, até o momento em que as atividades do rural têm suas ações baseadas no agronegócio, cujo objetivo era o desmatamento para a ampliação da área plantada, como analisado por Simione da Silva (2005). Mesmo assim, de acordo com Marx, esta seria uma segunda natureza, não urbanizada, mas modificada para fins de interesse de sobrevivência e principalmente do capital; modificação esta realizada pela exploração do trabalho nos espaços rurais, principalmente pela atividade agrícola, vinculada às elevadas concentrações de terra e à consequente expropriação camponesa.

O resultado desse processo são as constantes e históricas lutas pela terra e reforma agrária no Brasil, que redireciona também uma nova abordagem da relação entre o rural e o urbano, pois embora o problema se concentre na luta pela terra e seus conflitos em 
diversos níveis, e a luta pelo acesso a políticas públicas e ao Estado, o direcionamento desses processos ocorre nos centros de decisão política, localizados nas cidades, materializados pelo Estado em diversos âmbitos e nas instituições vinculadas à terra no país. O rural e urbano, nesse sentido, são territórios de luta dentro de um mesmo contexto; e, embora em lugares diferentes, correspondem a uma mesma estrutura organizacional, política e social, como analisam Oliveira (2004), Marques (2002) e Fajardo (2009).

Outro ponto a se considerar é a vertente analítica de tal relação, pois ela só tem efetividade se compreendida a partir das relações humanas, seus conflitos, interesses, colaborações, laços familiares, memória e construções. Tais relações são materializadas nos territórios desses espaços construídos ao longo do tempo, expressos na paisagem acumulada que representa o momento atual da relação entre o rural e o urbano, enquanto dinâmica territorial, construída por diferentes sujeitos.

Para a realização de tais estudos, opinamos que os mesmos sejam enfocados a partir de temáticas diferenciadas e complementares, uma vez que cada pesquisador pode inferir da realidade a partir de um determinado prisma analítico. Evidentemente que, ao tomarmos esse indicativo, as especificidades ficam delimitadas conforme as linhas de pesquisa de cada um, havendo a necessidade de a temática ser analisada multidimensionalmente, multitemporalmente e multiescalarmente nos territórios, considerando, além disso, a base material e imaterial dos territórios, de acordo com cada método empregado.

\section{DIMENSÕES E ENFOQUES ANALÍTICOS DO RURAL E DO URBANO}

Diversas são as temáticas possíveis para a verificação do homem na relação entre o rural e o urbano, diante da abordagem territorial ou do sujeito. Acreditamos que as vertentes que mais se aproximam da explicação da realidade são: a social, a política, a cultural, a econômica e a ambiental. Podemos analisá-las separadamente, em conjunto, ou relacioná-las, conforme as características de cada lugar, considerando sua dinâmica local/regional/global e o processo de construção do espaço. Mesmo separando-os, não podemos compreendê-los dicotomicamente, uma vez que são fruto de um mesmo processo de construção, sob facetas diferenciadas dialeticamente, a partir do espaço rural, formando um par dialético indissociável, mas cada qual com suas características próprias.

A relação rural-urbano sob o enfoque social pode considerar os diferentes conflitos de interesses sobre os espaços, como as questões agrária e urbana; o modo de vida e seu olhar nos espaços; os costumes; a resistência; a luta constante; a memória; a análise da dinâmica espacial-territorial dos sujeitos através do processo migratório e ocupação territorial; a questão da relação do ensino e da saúde nesse contexto; a questão de gênero, dentre outros. A divisão social e territorial do trabalho expressa a espacialidade do trabalho e as decorrentes problemáticas trabalhistas, sua exclusão e diversificação, assim como o processo de ocupação do espaço regular ou irregularmente. A questão social permeia todas as outras formas de análise dessa relação, pois as transformações dos espaços ocorrem através dos direcionamentos e interesses sociais. 
Já a perspectiva política considera os espaços e suas divisões administrativas e oficiais, que delimitam o ordenamento territorial urbano e rural dos municípios, assim como os interesses vinculados às divisões territoriais, e as relações de poder existentes entre tais espaços. Esta área está relacionada diretamente com as questões econômicas e sociais, considerando o processo de industrialização e mobilidade nos espaços intramunicipais, dependendo do caso. Os espaços periurbanos, os distritos, os acessos aos bens materiais públicos de primeira necessidade estão também diretamente vinculados.

A cultura expressa as relações materiais e imateriais dessa dinâmica, através dos sentimentos de pertencimento, identidade, modo de vida, religiosidade, sistemas de objetos e ações, tradição familiar, análise de monumentos/construções urbanas levantados em períodos onde o rural era mais representativo do que o urbano, na maioria dos casos; a transmissão de cultura material e imaterial ao longo do tempo, como os saberes tradicionais; o tradicionalismo e a relação com as técnicas no rural e no urbano; o consumismo; o turismo; o patrimônio rural, vinculado a lugares específicos e/ou comunidades tradicionais, entre outros.

O econômico permeia, assim como o social, todas as perspectivas, uma vez que, no modo de produção capitalista, a busca pelo capital é responsável pela sobrevivência da maioria das pessoas, mesmo considerando algumas famílias tipicamente camponesas no espaço rural, que sobrevivem de sua própria subsistência. Diante dessa perspectiva, o econômico pode ser analisado a partir da dinâmica espacial e territorial da produção agrícola e não agrícola em ambos os espaços, como a pluriatividade; os interesses de especulação fundiária e imobiliária pelo capital; o processo de modernização agrícola e a expropriação rural; a verificação da estrutura fundiária e urbana; as relações de trabalho na produção rural, vinculada diretamente aos interesses do capital nas áreas urbanas, assim como os centros organizacionais e decisórios; a divisão social e territorial do trabalho; o trabalho part-time; as atividades de extração e mineração; o acesso a políticas públicas e créditos, entre outros.

Nesta perspectiva, o sujeito ganha destaque na luta pela terra e na questão do trabalho, pois direciona uma perspectiva histórica de expropriação do trabalhador e de concentração fundiária, típicas do contexto espacial brasileiro.

Estes são apenas alguns apontamentos para o debate e pesquisa da verificação da economia na relação entre o rural e o urbano, já que muitas direções analíticas são possíveis. Vincula-se também à busca pelo desenvolvimento local, através das políticas públicas estatais, ou da construção de demandas das próprias sociedades rurais em cada território específico.

Já a questão ambiental ganha notoriedade a partir da década de 1990, mas sua expressão rural imbrica o urbano em sua construção, pois se relaciona com a questão da função do rural, baseada principalmente, em nossa perspectiva, na atuação da agricultura de base familiar na segurança alimentar, e, sob outro paradigma, na utilização do rural como forma de geração e reprodução do capital monocultor e industrial. Outras perspectivas analíticas podem ser fundamentadas também na geração e disposição de lixo, em sua maioria produzida no urbano e depositada no rural. A questão política de criação de 
reservas legais, as práticas agroecológicas, a mineração, a silvicultura, as áreas de ocupação irregular (crescimento da malha urbana), o saneamento básico do rural, entre outros tantos direcionamentos apontados para esse enfoque, como o uso da água na irrigação e a questão dos agrotóxicos, do assoreamento e eutrofização de rios e o desmatamento.

Entendemos a diferenciação entre o urbano e o rural como território usado, uma vez que o urbano foi construído pelas transformações e usos do rural. A questão ambiental permeia, portanto, tanto o campo quanto as cidades, pois nos dois espaços existem áreas de preservação, como parques, áreas de proteção permanente (APP), projetos de arborização e reflorestamento, áreas de reservas legais, e os remanescentes de florestas, que entrecruzam seus usos entre as atividades rurais e urbanas, assim como a agricultura urbana, que se encontra enraizada em diversas cidades, principalmente em áreas periurbanas.

Já a questão da escala geográfica é relevante no contexto das funções e atividades da relação do rural com o urbano, pois dependendo do tamanho dos municípios, da densidade populacional e das atividades vinculadas aos trabalhadores das cidades, a relação do rural com o urbano se intensifica, se funde ou se distancia. A caracterização e diagnóstico prévio da área de estudo são essenciais para a caracterização da relação do rural com o urbano, já que o sujeito é responsável pela dinâmica evidenciada entre esses espaços.

Não pretendemos, aqui, o aprofundamento dos enfoques e abordagens apresentadas no estudo da relação entre o rural e o urbano, mas apontar algumas perspectivas de análise metodológica, tendências e intensidades verificadas, considerando o inter-relacionamento dos aportes e enfoques apresentados no estudo do rural e do urbano de maneira relacional.

Estudar os espaços rural e urbano significa reestruturar a forma de refletir da sociedade em relação ao seu espaço de vida, de trabalho e de relações pessoais e materiais. Pensar tais espaços é conhecer a história de cada lugar, sua essência sentida através das paisagens nos diferentes territórios, compreendendo e vivendo suas relações e evolução ao longo dos tempos. O modo de vida nesses espaços compreende a forma com que as famílias se expressam no dia a dia, e que seus hábitos sejam reconhecidos e repetidos nas diferentes sociedades, buscando sua reprodução contínua, diante de tantas dificuldades introduzidas no contexto da reprodução do capital, principalmente no meio rural, oriundas, na maioria das vezes, dos espaços urbanos.

O rural e o urbano são expressões de dimensões da sociedade, num mundo onde o capital e a diversidade econômica são evidentes e o consumismo do modo de produção capitalista dificulta algumas decisões em minimizar os impactos do uso irregular do espaço, principalmente por considerar a diversidade espacial do uso do solo em território nacional (ROSAS, 2010).

Em regiões onde o capital penetrou no campo com o caráter desenvolvimentista monocultor, expropriou grande parte de famílias que vivem no e do lugar, necessitando diretamente de ações do poder público em suas diversas esferas, com resultados pouco expressivos, mas ressaltando o poder da oligarquia agrária em relação aos produtores rurais e aqueles que não conseguem produzir na terra. $\mathrm{O}$ desenvolvimento territorial rural, neste contexto, só poderia ser evidenciado se fosse desenvolvido e organizado 
localmente, a partir dos interesses e necessidades de cada grupo, e não imposto através de políticas pelos diferentes entes do poder público.

Embora existam diferenças materiais e imateriais evidentes entre os dois espaços, deve-se considerar nas análises dicotômicas que tais espaços coexistem dialeticamente, sendo produzidos de maneiras distintas, mas com interesses em comum, principalmente relatando a luta pela sobrevivência de sociedades rurais e urbanas que se encontram às margens do sistema capitalista, mesmo incluso neste território, mas não participando efetivamente de sua reprodução, assim como os anseios de reprodução do capital, que utiliza os recursos do rural como matéria-prima para sua produção, seja o solo, a vegetação, os minerais ou as águas superficiais ou subterrâneas.

\section{O RURAL E O URBANO NA PERSPECTIVA DA DINÂMICA TERRITORIAL}

Para compreender a relação entre o rural e o urbano, consideraremos a dinâmica territorial material e imaterial (FERNANDES, 2008), diante das perspectivas apontadas. Primeiramente, as áreas de fronteira material entre esses dois espaços, e principalmente o entrecruzamento dessa fronteira, que formam diversas relações pautadas em áreas de especulação imobiliária/fundiária, de ocupação/resistência, de indústrias margeando as rodovias, e do interesse municipal em nomear o crescimento urbano em detrimento do rural, pensando principalmente em fins econômicos/impostos.

Os municípios, como unidades políticas/administrativas, passaram a ter autonomia a partir da constituição federal de 1946, e se refere a todo espaço construído a partir das zonas rurais, dicotomizando o rural e o urbano para fins administrativos e de acumulação de capitais. Juntamente com tal divisão, o poder público pode redividir os municípios em distritos, para facilitar a administração ou por interesses diversos na fragmentação do espaço.

Dessa maneira, podemos dimensionar que a formação de cidades e vilas em adensamentos demográficos teve como principal premissa os fatores de ordem econômica, formando uma frente pioneira intencional, gerando comércios e atividades relacionadas a determinados ciclos de acordo com a ocupação do espaço.

A dicotomia criada representa justamente a relação entre o rural e o urbano no cerne de seu imbricamento, pois funda as bases para a construção de um espaço adensado a partir das relações rurais, direcionadas pela divisão do trabalho que compõe a estrutura de funcionamento da economia local naquele momento histórico, representando uma função atribuída e específica naquela circunstância.

A criação de espaços urbanizados e aglomerações, além da inserção de novas tecnologias, ampliou, aos poucos, a dicotomia entre o rural e o urbano. Porém, devemos considerar esse processo relacional de diferenças ou igualdades por meio das intensidades e necessidades, e não de contrastes (MARQUES, 2002). Tal ideia advém das particularidades e singularidades, considerando a existência de pontos extremos de uma escala de gradação. Nesse sentido, o rural e o urbano se aproximam, porém, mantêm as suas peculiaridades (WANDERLEY, 2001). 
Essa dicotomia teve início com a divisão social e territorial do trabalho que trouxe indicativos de produção específicos de cada espaço. Porém, as cidades, frutos dessa divisão, surgiram a partir de espaços rurais. "O ambiente urbano é, portanto, resultado de aglomerações localizadas em ambientes naturais transformados, e que para a sua sobrevivência e desenvolvimento necessitam dos recursos do ambiente natural." (PHILIPPI JR, ROMÉRO, BRUNA, 2004, p. 3). Segundo Mamigonian (1996, p. 204-5)

Diferentemente do que imaginam os funcionalistas (Durkheim), as relações cidadecampo não são simplesmente complementações de atividades, elas são geradas por desigualdades latentes e geram por seu turno novas desigualdades e conflitos de interesses. As cidades exploram os campos, retirando-lhes parte de suas produções a pretexto de proteção ou outra razão qualquer.

As desigualdades no espaço rural ganham novas perspectivas de análise, principalmente no que tange aos movimentos sociais no campo, que possuem nas cidades suas bases reivindicatórias. Tais abordagens são referenciadas por Marques (2002), Oliveira (2004), Simione da Silva (2005), Carlos (2004), Fernandes (2005), entre outros.

Tais diferenças ocorrem com intensidades distintas, em diferentes momentos e lugares. No Brasil, as mudanças no espaço rural tiveram maior significado em meados do século XX, trazendo mais elementos para o debate que se pretende tratar neste artigo. De acordo com Brose (2001, p. 14), o meio rural é composto por diversos elementos que se transformaram:

[...] da qual a agricultura é apenas um dos elementos constituintes. Ele é composto por fatores sociais (educação, religião, lazer, etc.), fatores econômicos (fontes de renda não-agrícola como o turismo, comércio, manufaturas, etc.), fatores políticos e outros setores diversificados, que compõem aquilo que convencionamos chamar de meio rural.

Enfatiza-se que tais transformações modificam a noção de rural e urbano, em caráter social, cultural, econômico e ambiental, rearranjando a noção dicotômica que permeava até meados do século XX. Neste aspecto, a "delimitação de fronteiras entre a cidade e o campo, a partir de uma classificação sustentada em atividades econômicas ou mesmo em hábitos culturais, se torna cada vez mais difícil”. (FIALHO, 2000, p. 9).

Para Moreira (2007, p. 94), “durante séculos a paisagem rural foi o quadro típico da arrumação geográfica das sociedades." Se for considerado em relação às áreas totais, materiais, atualmente tal paisagem também é predominante. Porém, a mudança gradativa da divisão de trabalho ocorreu e se acentuou devido à evolução das técnicas, estabelecendo novas mobilidades para as pessoas, que começam a criar e migrar para as cidades, alterando os vazios e acrescentando aos espaços novos significados.

Tal avanço do urbano sobre o rural tende a se enfraquecer, diminuir e até mesmo cessar com o tempo, devido à saturação imobiliária e a renda da terra, à diminuição gradativa da taxa de natalidade, aos preços abusivos praticados em áreas de fronteira pela 
especulação, além da legislação ${ }^{1}$ que rege o ambiente na atualidade, proibindo, pelo menos através de medidas legais, a utilização de áreas de proteção permanente, como matas ciliares, reservas naturais, além da degradação do solo devido ao seu uso irregular.

Mesmo considerando que o capital, ao se concentrar nas cidades, busca alternativas e novos espaços para se reproduzir, e a expansão horizontal das cidades seria uma dessas alternativas, assim como a verticalização, ressaltamos que a reprodução do capital também se consolidou nos espaços rurais no Brasil, e as articulações do campo estariam relacionadas, em diversos aspectos, com as conjunturas políticas das cidades.

Nota-se que rural e urbano fazem parte de um mesmo espaço, produzidos e utilizados de maneira diferente, e criando redes e mecanismos singulares e articulados. A necessidade de que as pessoas têm em se aglomerar para facilitar seu sustento e segurança, recriou o meio típico rural num processo de urbanização, com fatores explícitos que caracterizam um lugar como urbano, que são a infra-estrutura, a facilidade de relações entre as pessoas, o comércio local, as informações, a caracterização de um padrão cultural típico de uma sociedade consumista e alienada (não generalizando), e a atividade de domesticação e extrativismo fora do local onde as pessoas se abrigavam em seus habitats.

O urbano se formou a partir do rural, e criou tal separação, dicotomia e função, devido ao espaço que cada lugar é capaz de abranger. $\mathrm{O}$ antagonismo de um mesmo espaço só pode ser percebido no entendimento do que é, e qual a relação deste com o homem e com outros espaços. Essa separação é aparente e real ao mesmo tempo. Aparente, pois não há prospectos de sobrevivência de pessoas em áreas urbanas sem a presença de áreas rurais, não sendo verdade o processo inverso. Real, pois apresenta formas de uso do espaço distintas, porém, complementares, mas diversas nos interesses, conflitos, e até mesmo no sentido de valorização dos lugares, já que o meio urbano é, atualmente, mais bem valorizado que o rural, pelo menos em relação a transações econômicas e intensidade de fluxos existentes e funcionais nas cidades.

A construção do meio urbano e as aglomerações de pessoas no meio rural diante da formação de vilas, início de uma forma urbana, mesmo sem se tornar urbano legalmente, fazem com que suas culturas aflorem através do sentido imaterial, subjetivo, composto por ideias, hábitos, vontades e costumes, e principalmente na representação de seus objetos materiais, como suas casas, seus alimentos, utensílios, ferramentas, representando as necessidades e evolução cultural de uma comunidade, representando um patrimônio material e imaterial, típicos de um local, ou universalmente construídos, sendo patrimônios rurais, como a extração manual de leite, áreas de secagem do café, confecção de doces e pães, a religiosidade típica, dentre outros.

Embora haja necessidade, para a demarcação municipal, de uma fronteira entre o urbano e o rural para facilitar sua prática administrativa e regulamentação de impostos, é evidente que esta necessita de uma revitalização conceitual, a partir das características do uso dos espaços enquanto territórios e dos padrões culturais e materiais de cada indivíduo ou família, além do próprio fluxo existente entre as cidades e o meio rural munici-

1 A resolução CONAMA 369/2007 classifica algumas áreas como de interesse público, como as citadas neste. 
pal ou vizinho, e até mesmo de outras regiões, considerando a questão alimentar. Nesse sentido, Girardi (2008) propõe uma nova tipologia do rural e do urbano no Brasil.

Tal tipologia evidencia uma leitura crítica da delimitação entre o rural e o urbano, evidenciando suas diferenças e peculiaridades, baseada em níveis de intensidade, como observado em Marques (2002).

Diante dessa perspectiva, é certo que o espaço urbano deveria oferecer diversas oportunidades ao morador da área rural, como educação, saúde, trabalho, lazer, entre outros. Porém, tais ofertas não são comuns a todos, considerando as oportunidades, o conhecimento e principalmente os aspectos econômicos de acesso, assim como o atendimento e o preconceito, além do inchaço do sistema de infra-estrutura de saúde e educação, principalmente. Por outro lado, os moradores das cidades, principalmente das grandes metrópoles, veem no meio rural um subterfúgio de descanso, harmonia e tranquilidade à velocidade da vida urbana, ou seja, um lugar de tempo lento.

De acordo com Brunet et al (1992), rural é tudo aquilo que pertence ao campo, incluindo o que é agrícola e não-agrícola. Para os mesmos autores, a ruralidade pode ser definida como tudo aquilo que se relaciona à vida rural, como as condições materiais e morais da existência das populações rurais. Entende-se que a ruralidade se caracteriza como certo tipo de relações de produção entre a população e seu meio. Portanto, o espaço rural, que também é um espaço construído, é uma forma de organização social, baseada em cadeias de produção, e que não pode ser compreendida isoladamente, sem a presença de espaços urbanos, transformados através da própria natureza.

Para Galvão (1987, p. 10):

[...] o espaço agrário identifica-se por peculiaridades de organização, geradas não apenas pelas atividades produtivas nele exercidas num determinado momento, mas também por efeito de ações externas a ele, anteriores àquelas mesmas atividades e consubstanciadas na natureza socialmente transformada pelo homem, e coparticipante dessa transformação. Articulando-se assim ao urbano por laços que corporificam os mais diversos tipos de funções entre os dois espaços, o agrário não perde sua identidade nem se esvazia de conteúdo próprio que constitue (sic!) objeto específico de atenção da geografia agrária.

Não se pode considerar o meio rural apenas como sinônimo de agricultura, tampouco o meio urbano como um espaço não-agrícola. "Portanto, aquela ideia de associar o rural ao atrasado, ao isolamento e à tradição e o urbano ao progresso, à integração e à modernidade perderam seu sentido" (SCHNEIDER; BLUME, 2004, p. 4). Isso fica evidente quando se observa tais relações em regiões onde o capital usa o espaço rural voltado aos seus interesses, ligados diretamente a monoculturas, ou a criação de cooperativas, com a participação mais efetiva de uma grande parcela de cooperados que vivem do meio rural. Porém, vale ressaltar que existem diversas formas de cooperativas, sendo que muitas delas se constituem empresas capitalistas, e outras tentam sobreviver e se inserir dentro do sistema. 
Entendemos que a visão de Galvão (1995, p. 103) a este respeito é essencial para a compreensão das mudanças atuais na relação entre campo e cidade.

Forjadas em suas origens pela divisão social e territorial do trabalho imanente à produção de excedentes agrícolas, e moldadas em sua história por processos sociais e econômicos de "calibragem" entre produção e consumo, no campo e na cidade, mudam hoje, em sua estrutura e formato, as relações campo-cidade, engolfadas pelo processo globalizante e acelerado da urbanização.

Considerando algumas áreas rurais integradas com o setor industrial, em decorrência da localização industrial e das indústrias voltadas às atividades agrícolas, observa-se que ocorre uma mudança significativa do rural, mediante o uso das técnicas difundidas pela "Revolução Verde" e acentuadas no processo de globalização, através de áreas como as comunicações, juntamente com o emprego da tecnologia no propósito agrícola. Porém, essas mudanças possuem caráter excludente e segmentado, já que esse vínculo não ocorre em todo o território, mas em apenas naqueles cujo espaço foi adquirido pelo poder do capital, principalmente em áreas da grande região Centro-Sul do país, e em algumas áreas do Norte e Nordeste. "Cria-se, praticamente, um mundo rural sem mistérios onde cada gesto e cada resultado deve ser previsto, de modo a assegurar a maior produtividade e a maior rentabilidade possível." (SANTOS, 1999, p. 242).

Isso fica mais evidenciado por Sachs (1995), quando argumenta que o século XX não pode ser considerado o século da urbanização, diante das dificuldades de integração de milhares de refugiados e trabalhadores desarticulados economicamente e politicamente que vivem em um campo desintegrado e desagregado, não pertencendo nem ao meio rural, nem tampouco ao urbano. Neste contexto, Sachs (1995) denomina o processo de urbanização como "desruralização", uma vez que o processo migratório para as cidades, conhecido como êxodo rural, não significa integração socioeconômica dessas pessoas no meio urbano, ficando mais uma vez marginalizados, como ocorre em diversas cidades no Brasil.

Desse imbricado histórico, a relação entre o campo e a cidade se caracteriza através do sistema de produção, interligado por cadeias e redes de serviço, constituindo uma teia entre a indústria, o urbano e, essencialmente, o rural, que em determinadas regiões, formaria um grande elo de interligações e interdependências do urbano em relação ao rural. Nesse sentido, o capital, mesmo desagregador, volta a diminuir as distâncias entre o urbano e o rural por conta de seus interesses nesses dois espaços.

O impacto dos avanços tecnológicos na produção agropecuária em algumas áreas pode intensificar o desemprego no campo, sendo aplicável através de tecnologias criadas na cidade, mesmo que difundidas pela utilização no campo, modificando a dinâmica do espaço geográfico (do campo e da cidade). No campo, a reestruturação econômica e produtiva trazida pelo processo de globalização fez com que houvesse uma abertura dos mercados, acelerando as trocas e relações comerciais, intensificando a competitividade, com base em cadeias agroalimentares que comandam a produção e o comércio atacadista em nível global, restringindo-se a algumas regiões produtoras, e até mesmo países (SCHENEIDER, 2003), criando verdadeiros nós financeiros de um mercado global. 
Juntamente com o exposto, o avanço em pesquisas de biotecnologias faz com que apareçam contestações diversas ao padrão técnico dominante, principalmente dos expropriados do setor produtivo, como o acesso a tais recursos, ou o resultado futuro para a saúde humana do uso de organismos geneticamente modificados. As mudanças no processo de produção pós-fordista diminuem ou extinguem as diferenças setoriais e da produção territorial do trabalho. Dessa forma, o rural deixa de ser o lugar da produção agrícola, surgindo com ênfase diversas formas de complementação de renda e atividades não-agrícolas (GRAZIANO DA SILVA, 1999), considerando as diferenças regionais.

Ocorre, dessa forma, uma modificação nas relações entre o poder público e as sociedades rurais, aumentando as parcerias e diminuindo a centralização. Além disso, os problemas ambientais passam a ser enfocados de maneira diferenciada, além do que os recursos poderão ser utilizados como mercadoria e principalmente vantagem econômica, através da obtenção de créditos e fundos de investimento. Essas mudanças são efeitos diretos de uma reestruturação e mudanças ocorridas no Brasil, principalmente a partir de meados da década de 1990, que poderiam ser alongadas analiticamente, mas que, diante do necessário para a proposta deste trabalho, são suficientes para calcar expectativas e subsidiar explicações.

O campo e a cidade, cada um com suas especificidades, têm uma construção social do espaço, dentro de uma mesma lógica de produção, mas com interesses diversos no que tange as suas singularidades. Esses dois conceitos são frutos de diferentes conteúdos, bases formadas através do modo de vida e das oportunidades, que são o rural e o urbano, como explicitado anteriormente. A junção dos conteúdos aos referidos espaços, são configurados como espaço rural e espaço urbano, de acordo com seus respectivos sistemas de objetos e ações (SANTOS, 1999). Isso define que, tanto no campo quanto na cidade, pode haver características rurais ou urbanas, e isso se reflete no modo de vida e necessidade das pessoas, bem como no conjunto sistemático de objetos e ações desenvolvidas por elas. A materialidade é reflexo da subjetividade enquanto construção da memória e a execução prática das atividades.

A expressão e materialização desse conjunto de relações do rural e do urbano, cada qual em seu determinado espaço, são consideradas ruralidades e urbanidades, porém, essa lógica acaba transcendendo os "limites" do campo e da cidade, podendo ocorrer urbanidades no campo e ruralidades na cidade.

A conjunção de fatores do capital sob os espaços do campo e da cidade é resultado de diversos interesses que, mesmo considerando as peculiaridades de cada espaço, não veem diferenciação entre os mesmos, uma vez que a lógica do capital busca atribuir valores e redirecionar sua mais-valia de acordo com a rentabilidade, pela minimização de custos, ou seja, mesmo com suas características, o capital não escolhe o campo ou a cidade para realizar seus ganhos de valores, apenas os caracteriza conforme seus interesses e segmentos. Nesse sentido, é necessário compreender e analisar a formação desses espaços, sua natureza e estrutura, principalmente no meio rural.

Tudo o que é urbano foi um dia rural, mas nem tudo o que é rural será um dia urbano, dada a dimensão espacial e o crescimento populacional. Contudo, o avanço do 
processo de urbanização tem modificado muito o espaço rural em diversas partes do país e do mundo, principalmente aquelas onde a inserção do capital se faz com maior ênfase, e também próximos aos centros metropolitanos.

"Assim, mais do que o fato de a humanidade ser urbana vivemos como se devêssemos ser urbanizados." (PORTO-GONÇALVES, 2006, p. 181). O caráter capitalista de modernidade traz o urbano como sinônimo de progresso, fazendo com que o modo de vida rural seja sinônimo de atraso, de arcaísmo. Nesse sentido, a (i)lógica cultural e material imposta pela mídia faz com que as pessoas necessitem modificar seu modo de vida e busquem moradia em centros urbanos, pautadas no caráter industrial. Porém, apesar da permanência desse caráter ideológico capitalista urbano-industrial, de acordo com a Organização das Nações Unidas (ONU), em 2001 havia 53\% da população mundial vivendo em áreas rurais. Isso não significa que tais pessoas representem totalmente o caráter arcaico, pois o capital se aproveita do rural para recriar suas condições, principalmente com o uso de recursos visando à exploração da terra e do trabalhador, através da tecnologia implementada no campo.

Nesse sentido, Porto-Gonçalves (2006) sustenta que o processo que se firma não é de urbanização, mas de desruralização, já que as pessoas que se dirigem aos centros urbanos vivem em situações de miséria e submissão econômica, marginalização, expropriação e falta de oportunidades para o trabalho, criando e recriando áreas de favelas, de moradias periféricas sujeitas às ações das intempéries, de falta de infra-estrutura educacional, aumentando os índices de violência e tráfico de drogas. Portanto, essas pessoas não estão se urbanizando, mas se desruralizando, já que não vivem os padrões da urbanização (água, esgoto, energia elétrica, asfalto, telefone, televisão, entre outros), e criam uma nova fronteira entre o urbano e o rural, denominadas regiões deprimidas ou estagnadas, não sendo considerada urbana nem rural, mas uma nova área de subterfúgio de marginalizados do meio urbano e principalmente do rural. Essas transformações ocorrem em um palco específico, a natureza, um espaço construído historicamente, moldado de acordo com os interesses das sociedades de cada época e de cada lugar.

É nesse contexto que o entendimento do urbano é tomado como um processo em expansão. Portanto, tempo e espaço, determinados por um conjunto de relações que se imbricam nas áreas mescladas, e naquelas cujos mercados fazem parte dos produtos elaborados nas duas esferas. Já na perspectiva de Lefébvre (1999), a dicotomia rural-urbano está posta na construção da sociedade urbana, sendo que esta cria e recria as diferenças, expressando-as no rural, através da lógica de mercado elaborado no urbano.

O rural é penetrado pelas relações de mercado típicas das áreas urbanas, como expressado também por Figueroa (1997), que denomina o rural como mais um ramo de atividades em que o capital se insere e realiza suas reproduções.

\section{ESPAÇOS RURAL E URBANO: BUSCANDO NOVAS INTERPRETAÇÕES}

Quando se busca compreender, interpretar e analisar as características e relações dos/nos/entre os espaços rural e urbano observa-se a existência de diversas vertentes, 
construídas historicamente e pautadas em flancos distintos ou agrupados. Dentre outras, pode-se analisar as características do rural e do urbano na paisagem, nas relações sociais, culturais, de vivência, de uso do solo, econômicas - só para citar algumas - em tais espaços e na relação entre eles. Numa análise dos itens separadamente, possui-se mais facilidade na compreensão, porém, minimiza-se a constituição da realidade na esfera analítica, comprometendo um pressuposto de maior abrangência.

Tais perspectivas são mais evidentes na observação inicial da paisagem na área de transição entre o rural e o urbano. Primeiramente, numa abordagem visual, o rural e o urbano se distinguem em diversos aspectos, como a impermeabilização do solo para diversos fins, a pavimentação, a construção civil no urbano; e a maior presença de áreas naturais, atividades agropecuárias, menor quantidade de pessoas nas áreas rurais. Nesta perspectiva, não se pode criar uma dicotomia, considerando que as áreas urbanas já possuíram características rurais, e que a aglomeração de pessoas ocorreu gradativamente, e se tornou uma característica marcante da modernidade capitalista ocidental, e que a formação do espaço urbano ocorreu sobre o espaço rural ao longo dos tempos.

Neste aspecto, nota-se o crescimento das áreas urbanas em direção às rurais, na maioria das cidades onde há um maior investimento do setor público em áreas urbanas, ocasionando maior demanda de imóveis, constituindo supervalorização dos estabelecimentos rurais que se encontram nas adjacências das cidades. Além desse aspecto, ocorre a busca por reservas de valor através de estabelecimentos rurais na fronteira do rural e urbano oficial e a construção de residências para venda, em regiões prósperas economicamente, ou seja, onde há perspectivas de crescimento das atividades urbanas, em decorrência de investimentos em diversos setores, tanto urbanas como rurais.

Já sobre as relações sociais é evidente que a maior concentração demográfica em áreas urbanas vai propiciar mais relações na sociedade, isto é, haverá maior comércio, reprodução do capital, mobilidade de pessoas e interesses, conflitos. Tais interesses advêm da lógica do capital em alguns espaços, ou de reprodução e sobrevivência em outros. As relações são fruto de diversos aspectos culturais, ligados à lógica da família rural, às relações comerciais e às políticas públicas que direta ou indiretamente afetam essas pessoas.

\section{VISÕES SOBRE AS RURALIDADES NO BRASIL}

A ruralidade deve abranger a "problemática social da gestão do espaço e da reprodução das famílias de agricultores, aos aspectos relacionados à viabilidade econômica e produtiva dos negócios e transações comerciais" (SCHNEIDER; BLUME, 2004, p. 3), além da preservação dos patrimônios históricos e culturais e da utilização e preservação dos recursos naturais.

De acordo com Schneider e Blume (2004), o debate sobre a ruralidade pode ser dividido em quatro perspectivas distintas, mas que se relacionam e não são dicotômicas.

A primeira visão está relacionada aos aspectos demográficos e econômicos, e seus estudos estariam interligados numa análise separando a dinâmica social do espaço rural 
dos processos produtivos e econômicos, assim como a prática agrícola. Os principais estudos que se baseiam nessa perspectiva foram realizados por Graziano da Silva (1999) e outros pesquisadores ligados ao "Projeto Rurbano", enfatizando suas análises nas características dos novos mercados de trabalho rural agrícola e não-agrícola, vislumbrando seus impactos sobre a geração de renda familiar e sobre as economias locais.

Esse fato ocorreria devido à redução da população economicamente ativa ocupada na agricultura e, em contrapartida, o aumento das pessoas e famílias ocupadas em atividades não-agrícolas. Estes fatos decorrem de teorias que não pretendem explicar o rural como apenas atividades ligadas à agricultura, além da importância da pluriatividade, especialmente com relação às famílias rurais.

A segunda perspectiva se concentra nas análises das ruralidades voltadas aos aspectos sociológicos e etnográficos, buscando uma compreensão das relações voltadas à construção e redefinição das identidades sociais, culturais e do modo de vida. Ainda para Schneider e Blume (2004), essa perspectiva pode ser evidenciada principalmente nos trabalhos de Wanderley $(1997 ; 2001)$ e Carneiro (1998; 1998a; 2003), e exprime que o modo de vida encontrado nos pequenos municípios brasileiros evidenciaria a especificidade da ruralidade brasileira.

Para Wanderley (2001), mesmo considerando a análise do IBGE sobre a constatação de que todo pequeno município teria uma área urbana, baseado em critérios administrativos, na prática isso não ocorre, e esses municípios não funcionam como centros urbanos, pois mesmo considerando a inserção de tecnologia na agricultura e o processo de modernização comandado pela sociedade pós-industrial na cultura e nos modos de vida das pessoas, as pequenas localidades mantêm traços de suas especificidades rurais, distintas do modo de vida urbano de cidades maiores.

Para a autora, estudar a ruralidade significa compreender as relações dos modos de vida das coletividades locais, sendo que as características do modo de vida rural estariam ligadas às formas de produção, caracterizado pela precariedade e vulnerabilidade das cidades, como a falta de infra-estrutura, pela cultura, e pela resistência aos mecanismos desagregadores com que essa população estaria constantemente se confrontando (WANDERLEY, 2001). Dessa maneira, os pequenos municípios (com menos de 20.000 habitantes), seriam a expressão e a projeção da ruralidade no Brasil, e sendo a maioria, estaria ligada à grande parte do território do país, diferentemente do que indicam as estatísticas oficiais.

Coloca-se, porém, uma complementação à análise da ruralidade proposta por Wanderley (2001), já que, mesmo considerando necessário o estudo e a compreensão dos modos de vida das comunidades e coletividades locais, a partir da relação com a forma de produção da cidade, devem-se considerar também, num aspecto geográfico, tais relações com territórios vizinhos e poderes que estão diretamente ligados ao município analisado, sendo necessário remeter a análise em um contexto regional, onde as relações dos moradores do meio rural se encontram muitas vezes mais interligados com outros municípios do que com aquele em que se está inserido, considerando também as políticas públicas em âmbito estatal e federal. 
Uma terceira perspectiva ocorre com base nas dimensões atuais sobre a preocupação com a preservação ambiental e a sustentabilidade, de maneira a inserir no debate as formas de utilização dos recursos naturais e dos aspectos ligados ao meio. A relevância dessa visão está relacionada a diversas perspectivas, que passam pela legislação, a tomada de consciência e a forma com que os moradores do espaço rural aceitam ou não prerrogativas oriundas do urbano, já que o uso do solo, a erosão, o assoreamento e a contaminação das águas, assim como seu uso, além da utilização dos recursos florestais, passam necessariamente pelo meio rural.

Essa perspectiva engloba diversas interpretações, podendo-se citar autores como Guivant (1994) e Ferreira e Ferreira (2002) como referências, mas não como únicos, já que esta temática de uma nova caracterização do rural com bases na preocupação com os recursos naturais e a visionária sustentabilidade é expressão encontrada com ênfase nesse novo milênio.

A quarta vertente de análise se encontra na crítica tecida aos aspectos normativos da ruralidade, mais precisamente, no Brasil, voltada ao IBGE. No país, os critérios políticos e administrativos são a base para a definição da área rural e urbana pelo poder público local, voltada para a área física e de crescimento das moradias e loteamentos ao entorno do urbano.

O autor que mais analisou essa questão foi Veiga (2003), partindo do princípio de que a taxa de urbanização informada pelo IBGE no ano 2000, foi de $81,2 \%$, sugerindo que o Brasil é menos urbano do que se calcula, fato esse oriundo do Decreto-Lei Oficial n ${ }^{\circ} 311$, de 1938. Para isso, o autor propõe uma diferenciação do rural com o urbano baseado na densidade demográfica e no patamar populacional como alternativa, utilizando-se assim de critérios territoriais, baseando-se nas propostas da Organização de Cooperação para o Desenvolvimento Econômico (OCDE, 1998).

Nessa perspectiva, a análise do rural com o urbano não pode ser efetuada de maneira antagônica, como ocorre nos debates baseados no continuum ou da dicotomia ruralurbano, mas, sim, com caráter dialético, de complementaridade, onde as importâncias dos espaços são diferentes, assim como o próprio espaço, mas importantes igualmente para as sociedades.

Ainda para Veiga (2003), o novo critério de avaliação entre o rural e o urbano deve partir de uma análise com o enfoque territorial, já que os ambientes rurais e urbanos se diferenciam a partir do uso desses territórios pela ação antrópica, de acordo com o grau de artificialização desses espaços. Porém, ressalta-se que a utilização dos recursos naturais pelo homem nem sempre é baseada em densidades populacionais elevadas, uma vez que a monocultura latifundiária, assim como a exploração mineral, não são necessariamente concentrações populacionais, mas exploram veementemente tais recursos, às vezes muito mais do que quando ocorrem elevadas concentrações demográficas.

Diferentemente do que expõe Veiga (2003), observa-se que o que vale, portanto, não é a concentração de pessoas no território, mas o caráter, a intensidade e a abrangência do uso da natureza pelas pessoas e/ou empresas (que são compostas por pessoas, mas que têm nas máquinas sua maior margem de renda). Os homens não podem ser analisados 
somente por quantificações, mas pelo que representam e sentem a respeito dos lugares, seu trabalho, e a construção do espaço e pertencimento.

Já para Hespanhol (2006), existem três segmentos de pensamento, diferentes das abordagens, mas complementares e anacrônicas, que representam correntes de interpretação do espaço rural em relação ao urbano. A primeira considera a dicotomia campo-cidade; a segunda defende o fim do rural e a terceira exprime a existência de diversas ruralidades associadas aos universos culturais e econômicos distintos.

A tese que direciona a análise da dicotomia campo-cidade está baseada no separatismo de funções estabelecidas ao meio rural e ao urbano. Às cidades, caberia o papel de manter as indústrias e a prestação de serviços às pessoas nelas residentes, ou seja, os setores secundário e terciário seriam restritos às cidades. Já ao meio rural, estaria submetido o papel da produção agropecuária do setor primário, subsidiando a alimentação dos moradores das cidades. Porém, na atualidade, estas funções dos espaços não são mais totalmente aplicáveis, uma vez que existem diversas indústrias e funções não-agrícolas no meio rural, e atividades agrícolas no meio urbano, dentre outros argumentos.

Esta visão esteve muito presente no Brasil até a década de 1980, depois da consolidação da modernização da agricultura, mas ainda permanece em alguns setores, direcionando ao espaço rural a incumbência da produção agrícola para exportação e para a alimentação dos moradores das cidades, além da própria subsistência do campo. Mas o que vale ressaltar é a característica da produção existente e direcionada a cada espaço.

A segunda linha de pensamento, ainda de acordo com Hespanhol (2006), referese ao fato de a relação rural-urbano estar baseada no avanço do capitalismo no campo, levando a uma maior tecnificação desse espaço e consequentemente uma urbanização ou características urbanas nos espaços rurais, o que levaria a uma atrofização ou, mais radicalmente, a um desaparecimento do rural em detrimento do urbano. Juntamente com essa perspectiva, mas contrária a ela, a tecnificação do campo aproximaria os dois espaços, devido à dinâmica do capital e tecnologia aplicada nas atividades agrícolas, oriundas dos centros urbanos.

Moreira (2007, p. 95) salienta que:

Três fases se distinguem nesse processo que torna o mundo inteiro uma civilização urbana: na primeira, a cidade se separa do campo; na segunda, a cidade se torna o grande polo da concentração populacional; por fim, na terceira, a cidade invade e urbaniza o campo com sua cultura.

Tal argumentação se solidifica na existência do fim do isolamento entre cidade e campo, através de um continuum rural-urbano, onde as características, modo de vida, influências econômicas são repassadas do urbano para o rural, transformando-o e levando a uma perda constante das características do rural, devido à imposição das características urbanas em diversos planos, até mesmo em áreas mais marginalizadas do espaço rural. (WANDERLEY, 1997; 2001).

Para Graziano da Silva (1999), o campo adquire novas características e funções, que surgem com o objetivo de atender a crescente demanda de consumo. Porém, esse 
novo rural não é apenas visado através de atividades não-agrícolas, mas de uma relação baseada no avanço capitalista em todos os setores de atividades, levando a uma adaptação e uma crescente demanda de consumo pelas cidades, como a criação de plantas, animais exóticos, peixes, minhocas, entre outros, caracterizando e vislumbrando atividades pluriativas nestas famílias rurais.

Esta ideia é repassada também por Medina (2004), quando refere que a tecnologia é o fator principal que leva a uma uniformização da sociedade e do espaço rural, seguindo os padrões do meio urbano, ou seja, todos os espaços são afetados pela globalização tecnológica, econômica e cultural. Seria a tendência à homogeneização dos lugares, mas que, de acordo com Santos (1999), nunca chegaria a acontecer, pelo contrário, os lugares se tornariam cada vez mais específicos.

De acordo com Alves (2001), o fenômeno de urbanização do campo é mais evidente nos países desenvolvidos, e que no Brasil ocorre um processo em médias e parte de grandes cidades de ruralização do urbano, principalmente nos locais onde se instalam pessoas provindas de um processo migratório em busca de emprego e consequentemente melhores oportunidades e condições de vida. Porém, nota-se que a ruralização do urbano ocorre em pequenas cidades. Esta vertente é também defendida por Zabotto e Oliveira (2004), que incluem que esta mistura entre culturas e necessidades ocorre principalmente nas áreas periféricas das cidades, local onde se assentam os migrantes do meio rural.

A terceira linha de pensamento da relação campo-cidade apontada por Hespanhol (2006) considera que, embora existam diversas implicações sobre o rural, há a permanência de áreas com características próprias e com grau de inserção na dinâmica econômica diferenciada, conforme processo de desenvolvimento histórico de cada lugar, gerando diferentes ruralidades e territorialidades nestas regiões.

De acordo com Carneiro (1997, 1998, 1998a), apesar de haver uma maior comunicação entre o rural e o urbano, em decorrência dos valores atribuídos a cada lugar, as fronteiras entre estes espaços passam a se tornar mais imprecisas, mas longe de se homogeneizar, pois cada qual continua com suas especificidades, de acordo com a região e com o processo de ocupação socioeconômica e relações externas de cada lugar.

Nesse sentido, Santos (1988) considera que o processo de globalização não homogeneíza os lugares, mas os tornam mais específicos. Já para Boxberger e Klimenta (1999), no sentido do mercado e das informações, enfatizam que a globalização não promoveu a diversidade, mas um padrão de consumo e informação, de acordo com a lógica do mercado.

Porém a ideia de especificidade dos lugares e de revitalização particularizada é estendida a Saraceno (1994), Marques (2003), Tavares (2005), Ferrão (2000), entre outros.

Fica claro que o padrão de desenvolvimento territorial adotado leva a uma maior inter-relação entre o rural e o urbano, dependendo da região e das características indicadas em cada um desses espaços, porém, os lugares passam a se tornar mais específicos e únicos (SANTOS, 2000), restaurando padrões de produção e criando condições alternativas à crise da agricultura (ou diminuição dos lucros) provinda, sobretudo a partir do fortalecimento 
do movimento de modernização do campo e a consequente marginalização de produtores rurais com menores condições de produção.

Acredita-se que as perspectivas de análises do meio rural estão subjugadas e interligadas, uma vez que tais separações servem apenas para estudos baseados em diferentes perspectivas e visões, porém, os acontecimentos vão ocorrendo empiricamente sem depender de análises diversas sobre o tema, que ocorrem principalmente na seara acadêmica. Considera-se importante que haja uma integração das análises baseada nas diversas perspectivas apresentadas, para que se consiga a compreensão da dinâmica do rural brasileiro, caracterizando-o como novo, não por apresentar especificidades diferentes das passadas, como seria comum que acontecesse, mas apenas como um novo cronológico, no sentido de mudanças realizadas no processo de construção desse espaço, que possui lógicas diversas e interesses de usos distintos.

As técnicas são um dos principais elementos na reestruturação produtiva, o que aumenta a divisão social e territorial do trabalho. Há uma remodelação do território, e uma reorganização dos sistemas rurais e urbanos. Embora o padrão tecnológico influa nas características dos espaços, há regiões e padrões considerados arcaicos que se misturam e convivem lado a lado com tal avanço, principalmente em áreas onde a agricultura de base familiar, juntamente com as dificuldades produtivas, são mais afloradas.

\section{REFERÊNCIAS}

ALVES, T. Plurifuncionalidade e desenvolvimento nas áreas rurais em Portugal. COLÓQUIO HISPANOPORTUGUÊS DE ESTUDIO RURALES, 4., Santiago de Compostela: Centro de Estudos Geográficos, Universidade de Lisboa, 2001. Disponível em: <http:/ / www.isega.es>. Acesso em 29/05/2005.

BLUME, R. Território e ruralidade: a desmistificação do fim do rural. Porto Alegre,RS. Dissertação (Desenvolvimento Rural). Universidade Federal do Rio Grande do Sul: Faculdade de Ciências Econômicas, Porto Alegre, 2004.

BOXBERGER, Gerald; KLIMENTA, Harald. As dez mentiras da globalização: alternativas para combater o mercado todo poderoso. São Paulo: Aquariana, 1999.

BROSE, Markus. Desenvolvimento Rural: potencialidades em questão. In: ETGES, Virgínia E. (Org). Desenvolvimento rural: potencialidades em questão. Santa Cruz do Sul-SC: EDUNISC, 2001. p. 11-17.

BRUNET, R., FERRAS, R., THERY, H. Les motes de la Géographie: dictionnaire critique. Paris: Reclus. La documentation française, 1992.

CARNEIRO, Maria José. Agricultura, meio ambiente e turismo: desafios para uma agricultura multifuncional (Nova Friburgo - RJ). In: CARNEIRO, M. J. e MALUF, Renato. Para além da produção: multifuncionalidade e agricultura familiar. Rio de Janeiro: MAUAD, 2003.

. Camponeses, agricultura e pluriatividade. Rio de Janeiro: Contracapa Livraria, 1998.

CARLOS, A. F. A. O espaço urbano: novos escritos sobre a cidade. São Paulo: Contexto, 2004.

FAJARDO, Sérgio. A questão locacional na relação campo-cidade. In: Dossiê relações campo-cidade, temas \& matizes. No 16, segundo semestre de 2009. p. 97-114.

FERNANDES, Bernardo Mançano. Questão agrária: conflitualidade e desenvolvimento territorial. In: BUAINAIN, A. M. (org.). Luta pela terra, reforma agrária e gestão de conflitos no Brasil. Campinas: Unicamp, 2005. 
Entrando no território dos territórios. In: PAULILO, E. T.; FABRINI, J. E. (orgs.). Campesinato e territórios em disputa. São Paulo: Expressão Popular, 2008. p. 273-301.

FERRÃO, João. Relações entre mundo rural e mundo urbano: evolução histórica, situação actual e pistas para o futuro. EURE (Santiago-Chile), Vol 26, n 78, Set. 2000. p 123-130.

FERREIRA, L. C.; FERREIRA, L. C. Águas revoltas: um balanço provisório da sociologia ambiental no Brasil. BIB, RJ, nº 54, 2002. p. 83-100.

FIALHO, Marco A. V. Agricultura familiar e as rendas não-agrícolas na região metropolitana de Porto Alegre: um estudo de caso dos municípios de Dois Irmãos e Ivoti - RS. Porto Alegre: UFRGS, 2000. Dissertação em Economia Rural. 206 p.

FIGUEROA, A. Hacia un nuevo enfoque sobre el desarrollo rural em Amércia Latina. In: Seminário internacional interrlación rural-urbana y desarrollo descentralizado. Taxto - México: FAO/ONU, 1997.

GALVÃO, Maria do Carmo C. Contribuição ao debate sobre perspectivas teórico-metodológicas para a geografia agrária. 17p. (texto inédito apresentado no $8^{\circ}$ Encontro Nacional de Geografia Agrária). Barra dos Coqueiros, SE, 1987.

As múltiplas facetas do espaço agrário contemporâneo no Brasil. In: (?). A Geografia e as transformações globais: conceitos e temas para o ensino. Rio de Janeiro: UFRJ, 1995. p. 101-116.

GIRARDI, Eduardo Paulon. Proposição teórico-metodológica de uma cartografia geográfica crítica e sua aplicação no desenvolvimento do atlas da questão agrária brasileira. Presidente Prudente: UNESP, 2008 (Tese de Doutorado).

GUIVANT, J. S. Encontros e desencontros da sociologia rural com a sustentabilidade agrícola: uma revisão bibliográfica. BIB, RJ, nº 38, 1994. p. 51-78.

GRAZIANO DA SILVA, J. O novo rural brasileiro. 2. ed. Campinas: Ed. Unicamp, 1999.

HESPANHOL, Antonio Nivaldo. Perspectivas regionais da análise cidade-campo. In: II Encontro de grupos de pesquisa - Agricultura, desenvolvimento regional e transformações sócio-espaciais. Uberlândia: UFU, 20 a 22 de jun, 2006. CD ROM.

LEFEBVRE, Henri. A revolução urbana. 34. ed. Belo Horizonte: UFMG, 1999.

MAMIGONIAN, Armen. Notas sobre a geografia urbana brasileira. In: SANTOS, Milton (Org.) Novos rumos da geografia brasileira. 4. Ed. São Paulo: Hucitec, 1996.

MARQUES, M. I. M. O conceito de espaço rural em questão. Terra Livre. São Paulo: AGB, n.19, jul./dez. 2002, p.95-112. Disponível em:

<www.cibergeo.org/agbnacional/terralivre19/6_O_conceito_de_espa_o_rural_em_questao.pdf>. Acesso em: 08/06/2005.

MARQUES, R. Os trilhos da nova sociologia econômica. In: PEIXOTO, j.; MARQUES, R. (Orgs.). A nova sociologia económica. Oeiras, Portugal: Celta Editora, 2003.

MEDINA, José Somoza. Implicaciones territoriales del desarrollo rural. In: Espacios y desarrollos rurales: una visión múltiple desde Europa y Latinoamérica. Trea: Gijón, 2004.

MOREIRA, Ruy. Pensar e ser em geografia: ensaios de história, epistemologia e ontologia do espaço geográfico. São Paulo: Contexto, 2007.

OLIVEIRA, Ariovaldo Umbelino de. Geografia Agrária: perspectivas no início do século XXI. In: OLIVEIRA, A. U.; MARQUES, M. I. M. (org.). O campo no século XXI: território de vida, de luta e de construção da justiça social. São Paulo: Casa Amarela/Paz e Terra, 2004. p.29-70.

PHILIPPI JR, Arlindo; ROMÉRO, Marcelo A.; BRUNA, Gilda Collet. Uma introdução à questão ambiental. In: PHILIPPI JR, Arlindo; ROMÉRO, Marcelo A.; BRUNA, Gilda Collet (Editores). Curso de gestão ambiental. Barueri: Manole, 2004.

PORTO-GONÇALVES, Carlos Walter. A globalização da natureza e a natureza da globalização. Rio de Janeiro: Civilização Brasileira, 2006. 
ROSAS, C. A. F. A (des)construção da dicotomia rural-urbano no Extremo Noroeste Paulista. Uberlândia: UFU, 2010. Tese de Doutorado. $246 \mathrm{f}$.

SACHS, I. À la recherche des nouvelles stratégies de développement. Enjeux du sommet social. MOST. Document des politiques sociales. Paris: UNESCO, $\mathrm{n}^{\circ} 1,1995$.

SANTOS, Milton. Metamorfoses do espaço habitado. São Paulo: Hucitec, 1988.

. A natureza do espaço: técnica e tempo, razão e emoção. 3. ed. São Paulo: Hucitec, 1999.

SARACENO, Elena. Recent trends in rural development and their conceptualisation. Journal of Rural Studies, V. 10, n 4, p 321-30, 1994.

SCHENEIDER, Sérgio. Teoria social, agricultura familiar e pluriatividade. In: Revista brasileira de Ciências Sociais. Porto Alegre, Vol. 18, nº 51, 2003. p. 99-121.

SCHENEIDER, S; BLUME, Roni. Ensaio para uma abordagem territorial da ruralidade: em busca de uma metodologia. II Seminário internacional sobre desenvolvimento regional. UNISC: Santa Cruz do Sul, RS, 28/08 a 01/09 de 2004.

SIMIONE DA SILVA, S. Resistência camponesa e desenvolvimento agrário na Amazônia acreana. Presidente Prudente, 2005. Tese (Doutorado em Geografia) - Universidade Estadual Paulista, 2005.

TAVARES, L. A. As fronteiras do espaço rural: uma concepção normativo-demográfica. RA'EGA. Curitiba: Ed. UFPR, n.7, 2003, p.33-46. Disponível em: <http://calvados.c3sl.ufpr.br/raega/include/getdoc. php?id=38\&article=17\&mode=pdf $>$. Acesso em 10/12/2005.

VEIGA, José Eli da. Cidades imaginárias: o Brasil é menos urbano do que se calcula. 2. ed. Campinas-SP: Autores Associados, 2003.

WANDERLEY, M. N. B. O "lugar" dos rurais: o meio rural no Brasil moderno. In: Congresso brasileiro de economia e sociologia rural. 35, 1997, Natal. Anais, Brasília: SOBER, p. 90-113, 1997.

. A ruralidade no Brasil moderno; por um pacto social pelo desenvolvimento rural. In: GIARRACCA, Norma. (Org.). Una nueva ruralidad en America Latina? Buenos Aires, 2001, p. 31-44.

ZABOTTO M. C.; OLIVEIRA, B. A. C. C. Rural e urbano: verso e reverso da mesma moeda. Território \& Cidadania, n. 2, jul.-dez./2004. Disponível em: <http://ns.rc.unesp.br/igce/planejamento/ territorioecidadania/Artigos/Zabotto1.htm>. Acesso em 11/12/2005.

Recebido em 18-03-2014

Aceito para publicação em 20-03-2014 